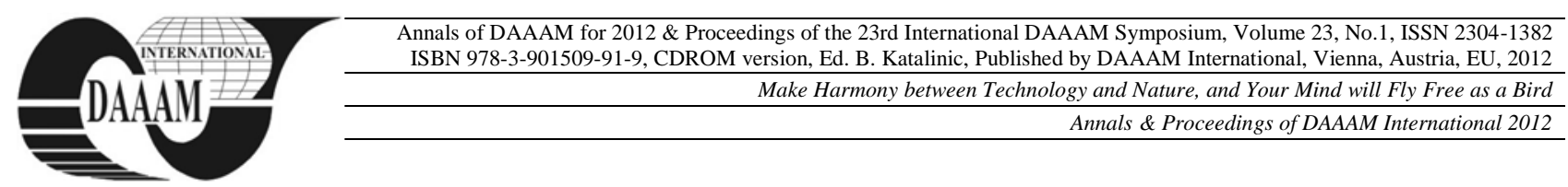

\title{
THE IMPACT OF ADVERTISING ON CONSUMER BEHAVIOR IN THE RESITA CITY POPULATION
}

\author{
DINU, G[abriel] \& DINU, L[oredana]
}

\begin{abstract}
This paper aims to highlight the importance of advertising on consumer behavior. The paradigm of economics is that consumers will maximize their own utility and will prefer low-costs, high quality products to high priced, added valuebrands. Marketing managers are driven by the need for consistency which is an innate of their own influences.

Keywords: online advertising, commercials, consumer behavior, research, fairs, exhibitions
\end{abstract}

\section{INTRODUCTION}

In the latest decades, one of the essential problems of manufacturing companies is the knowledge of how the consumer will respond to various things that will be used for achieving their ultimate goal.

The study of consumer behavior became a concern of marketers, as they may learn how consumers choose their goods and services required to meet multiple needs, which are the factors that are influencing their choice.

The increasing complexity of economic life, has led to the necessity of knowledge of human economic behavior mechanism which is becoming larger and more complicated, requiring separate study of the two intrinsic components: human behavior as a producer of goods and services and the consumer's behavior.

\section{METHOD}

Considers reasons why consumer response has, at best, been mixed with regard to postmodern marketing. Proposes reasons why consumer response has not been overwhelmingly positive and then, based on a review of key research findings, presents guidelines for the development of the components costumer behavior influencing by product advertising: the specificity of the marketing, the level of emphasis given the costumer behavior and the context for influences. [1]

For the contemporary society, where the technical progress tends to replace manufacturer-man with the manufacturer-the car becomes very important and significant study of behavior, as more as the scarce resources with alternative uses that the human society has require the production, only those goods and services that will meet the necessary quantities. Therefore, knowledge and explaining consumer behavior and purchasing has become an urgent necessity, ignoring how the manifestation of it, causing serious problems.
Each and every product delivers the different meaning to each user. User behavior is not related what consumer buy, but also with what they buy it. It depends on those factors which inclined the behavior of user or buyer. Culture, family and brand image these all factors influenced the buying behavior. Market share of the product depend on the awareness of consumer. That's why the organizations and agencies advertise their product via media either electronic or print or both. The repetition of advertisement and economic factor like per capital income also change the consumer behavior about to choice the product. [2]

Because the consumer's behavior is manifested on the market, it becomes a major study of marketing.

I have studied the way in which the advertising influences consumer's behavior. The shape of how the study was done was build by the survey conducted on a representative sample for the population of Resita.

The research was done on a representative sample of 366 people (quantitative research) in the population of Resita

The main objectives in the research were:

- the position of subject of how advertising influences their purchasing decisions

- the consumer's tastes on offer in online stores

- highlighting the main techniques of promotion for the supply

-highlighting how a company can become known

To treat the problems studied and consistent support to ensure a proper scientific work, we used some scientific research methods that can be mentioned among the methods of data collection and organization of the interview, questionnaire, observation, information visits and direct observation, statistical analysis the questionnaire, the distribution of values of a variable, numerical procedures for testing normality, univariate statistical analysis of data, the correlation method, regression, testing the difference between two proportions. [3]

Make marketing is, first, to apply principles of managerial efficiency in relation to consumer behavior

Knowing the fact that the goal of research is studying how advertising affects consumer behavior was 
considered appropriate as a form of research survey on a representative sample population of Resita.

Advertising can help companies develop consumers' awareness to an unmet need or introduce a product that consumers may see as valuable. This influence is often present when new products enter the market. Customer awareness is often low for these items until companies promote them and attempt to drive customer demand through advertising.

Seeing the role of advertising in selling products, most subjects $(59.11 \%)$ stated that advertising plays an important role in selling products, $(58.91 \%$ male, $59.29 \%$ women). Of all respondents $(30.47 \%)$ reported that little advertising plays an important role in selling products of which (38.51\& male, 27.64\%women). Only (10.42\%) did not believe that advertising plays an important role in selling products.

Speaking about the age, young people under 20 years $(67.74 \%)$ believe that advertising plays an important role in selling products, with those between 50-59 years $(60.86 \%)$ and those who didn't believe that advertising plays an important role in selling products.

Speaking about the occupation, those who agree that advertising plays an important role are pupils / students $(67.75 \%)$ and intellectuals $(64.40 \%)$ and those who don't believe at all in advertising are intellectuals $(3.40 \%)$ and pupils/students $(4.3 \%)$ workers $(13.80 \%)$ as well as other occupations $(13.80 \%)$.

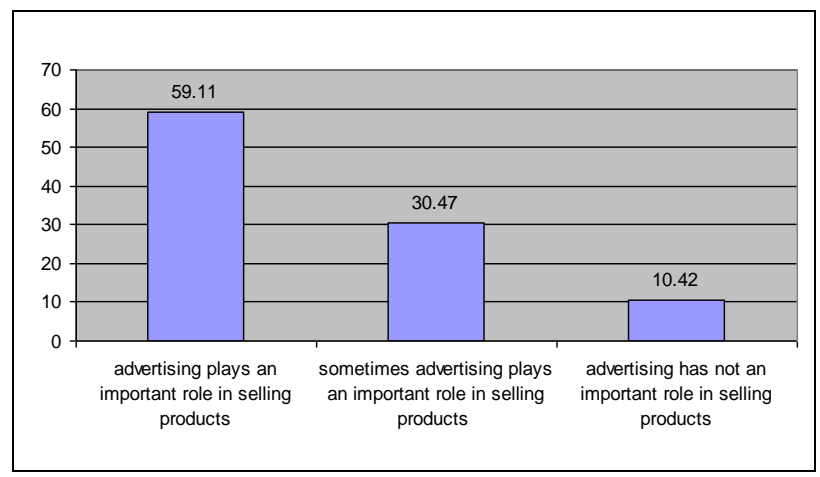

Fig. 1. The role of advertising in selling products

Most respondents (46.35\%) used to buy branded products, of which ( $45.40 \%$ male 47.23 women). Of the respondents $(43.75 \%)$ say they sometimes used to buy branded products $(44.86 \%$ male $42.71 \%$ women). Only $9.90 \%$ of subjects surveyed say they never buy branded products $(9.74 \%$ male $10.06 \%$ women)

Regarding the age, young people under 20 years $(68.81 \%)$ and those between $40-49$ years $(51.51 \%)$ say they buy branded products, and people over 60 years (68.42\%) and people between $20-29$ years $(50.84 \%)$ say they sometimes buy branded products. Those who never buy branded products are people under 20 years $(2.16 \%)$ with those between $30-39$ years $(6.36 \%)$.

Speaking about the occupation, those who buy branded products are pupils/students (68.81\%), intellectual $(66.10 \%)$ and officials $(44.06 \%)$ and those who never buy branded products are intellectuals $(3.40 \%)$ and pensioners $(7.02 \%)$.

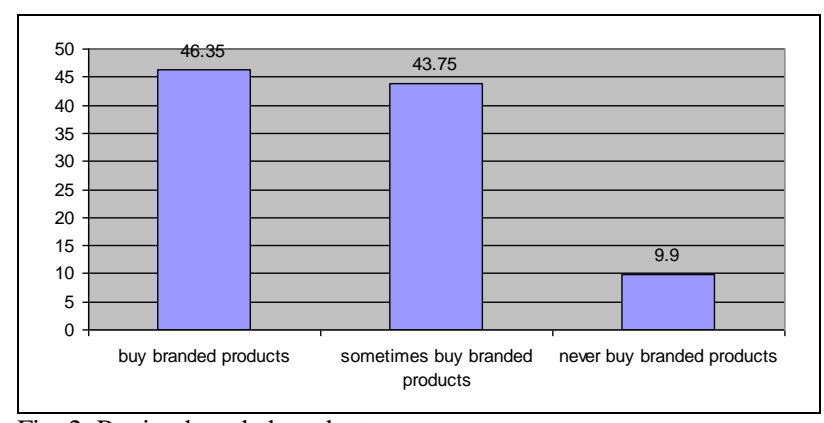

Fig. 2. Buying branded products

The subjects interviewed $(46.35 \%)$ are influenced by temporary price reductions when buying a product (48.10\% male $45.72 \%$ women). Of all respondent (36.72\%) of which (32.43 male $40.70 \%$ women) said they sometimes are influenced by temporary price reductions. Only $(16.41 \%)$ of respondents say they are rarely influenced by temporary price reductions when buying a product.

Speaking about the age, people under 20 years $(54.83 \%)$ and over 60 years $(80.70 \%)$ said they sometimes are influenced by temporary price reductions. Those who are sometimes influenced by price reductions are those between 30-39 years (55.55\%) and those between $40-48$ years $(42.42 \%)$, those who rarely influenced the decision to purchase discounts are young people under 20 years $(10.77 \%)$ and people over 60 years $(5.27 \%)$

Speaking about the occupation, those who are often influenced by price reductions are pupils/students $(54.83 \%)$, and those who rarely influences discounts when buying a product are pupils/students $(10.77 \%)$ and retired $(5.27 \%)$.

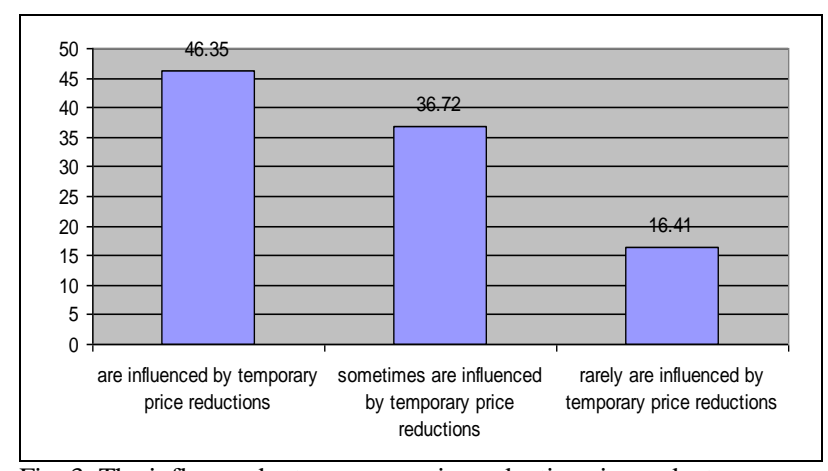

Fig. 3. The influence by temporary price reductions in products acquisition

The sponsorship can have a positive effect on product sales said most subjects interviewed $(42.97 \%)$. Of all respondents $(42.19 \%)$ say they sometimes sponsorship can have a positive effect on sales of products $(43.78 \%$ male $40.70 \%$ women). Only (14.84\%) do not believe that sponsorship can have a positive effect on sales of products $(14.60 \%$ male $15.08 \%$ women $)$. 
Speaking about the age, young people under 20 years $(64.51 \%)$ and people over 60 years $(59.64 \%)$ have said yes, and those who sometimes think that sponsorship can have a positive effect on sales of products are those between 30-39 years $(66.66 \%)$ and those between 40-49 years $(51.51 \%)$ and those between $20-29$ years $(44.06 \%)$. Those who believe that sponsorship can have a positive effect on sales of products are those between 30-39 years (9.54\%), young people under 20 years $(9.67 \%)$ and people over 60 years $(7.03 \%)$.

Those who believe that sponsorship can have a positive effect on sales of products are pupils/students (64.51\%) and intellectuals (44.08\%), those who argue that sponsorship can sometimes have a positive effect on other products are others occupations $(67.24 \%)$ and employees(47.45\%)and those who don't believe are pupils/students $(9.69 \%)$ and pensioners $(7.03 \%)$.

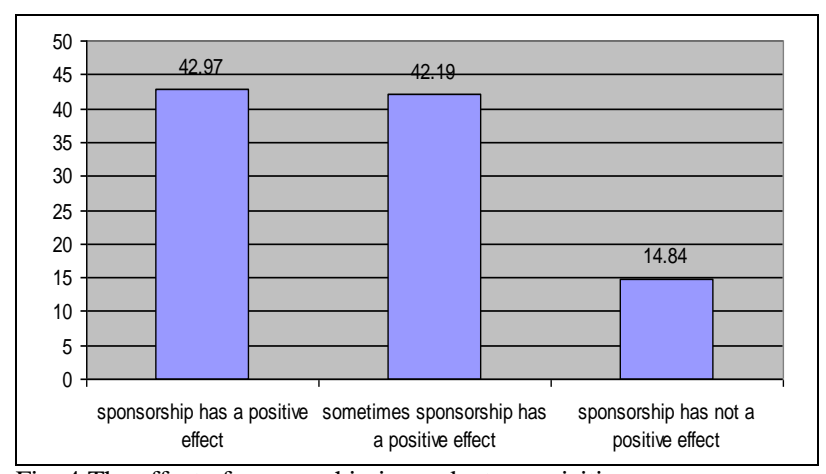

Fig. 4 The effect of sponsorship in products acquisition

The total sample of subjects interviewed (32.29\%) said they purchase products might cause you to go to fairs and exhibitions (23.24\% male, $40.70 \%$ women). Most of the subjects interviewed (42.44\%) are determined to go to fairs and exhibitions because products and prices ( $44.86 \%$ male, $40.20 \%$ women), and those who said that many products would may determine to go to fair and exhibitions (25.27\%) of which (31.50\% male, $19.10 \%$ women).

Speaking about the age, those who are determined by the purchase of new products are young people under 20 years $(45.16 \%)$ and those between $30-39$ years (38.09), those prices are determined by the manufacturer to fairs are people between 20-29 years ( 54.23\%) and those between 40-49 years ( (43.94\%) with pensioners $(61.40 \%)$, people who are determined by the multitude of products are those between $50-59$ years $(32.62 \%)$ and 40 49 years $(33.34 \%)$.

Speaking about the occupation, those who said they could cause him to go to fairs and exhibitions and purchase of new products are pupils/students (45.16\%) and intellectuals (45.76\%), those who said they go to fairs and exhibitions only because are producers and prices are the retired $(61.40 \%)$, other occupations $(48.27 \%)$ and workers $(46.55 \%)$ and those who are attracted by the multitude of products at fairs and exhibitions are the officials ( $23.73 \%$ ) and workers (41.39\%).

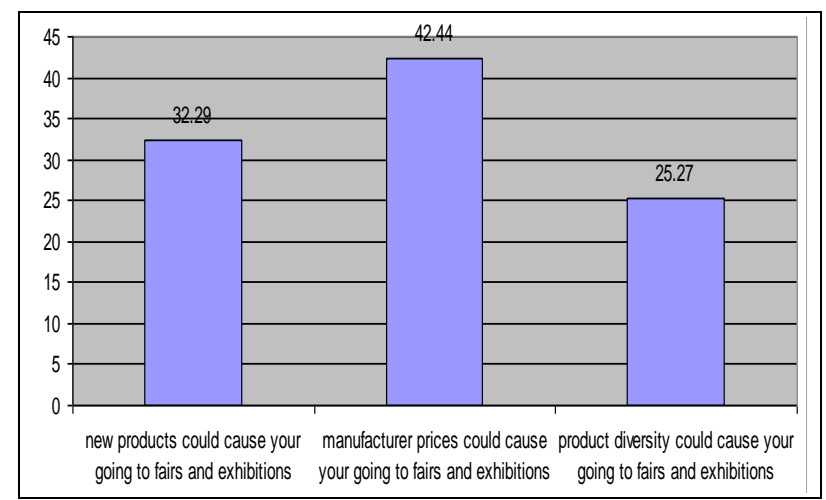

Fig. 5 The between purchase products and exhibitions

The total sample $(42.70 \%)$ said that most often are influenced by advertising on the Internet when buying a product $(43.78 \%$ male $41.70 \%$ women), those who said they are influenced by advertising on Internet (35.93\%) of which (32.97\% male 38.69\%women). Only (21.37\%) say that they are never influenced by the Internet.

Speaking about the age, people over 60 years $(64.91 \%)$ and those between $20-29$ years $(62.71 \%)$ say that are influenced by advertising on the Internet. Those people that are never influenced are between 20-29 years $(6.79 \%)$ and people over 60 years $(8.78 \%)$.

Speaking about the occupation, those who said they are influenced by advertising on Internet are intellectual (44.06\%) and pupils/students (41.93\%). Those who are not influenced by online advertising are retired $(8.78 \%)$ and employees (16.95\%).

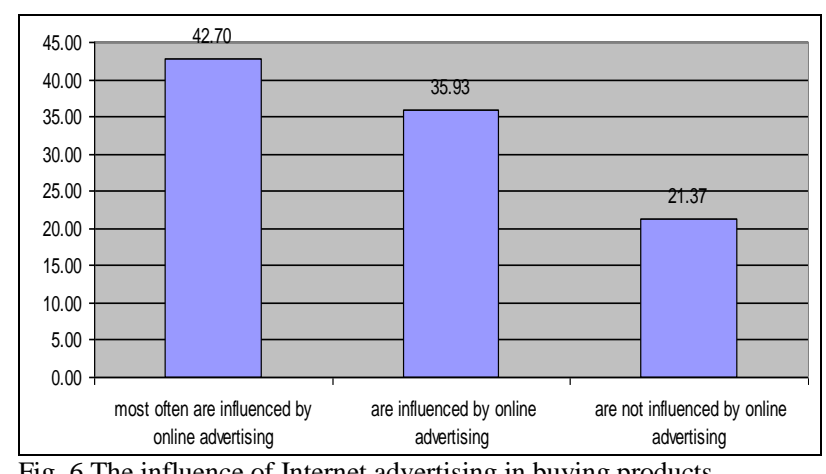

ig. 6 The influence of Internet advertising in buying products

\section{RESULTS AND DILEMMAS}

Consumer behavior research marks the progress every year, gaining new approach.

The online advertisement influences the desire to buy this being a known affinity for Romanians who look up information on the web.

The biggest publicity consumers on this platform are the computer companies, bank, mobile phone companies, insurance companies, the mass-media, the e-commerce companies and last but not least the internet providers.

The advertising market will grow in Romania, but it needs a bigger amount of transparency upon this market and also upon the benefits of using online advertising as a way of promoting (hit groups, target commercials, the 
possibility to filter the ip addresses and the report between efficiency and price).

The Romanians are used to buy brand products although the incomes do not recommend this. They are influenced, most of the times, by the sales put up by the producers.

The sales activate in the mind of the Romanians a great desire to buy. We have to admit that a shop window with a big $50 \%$ off can attract anyone. If in the sales period, two thirds of the Romanians do their shopping and in the rest of the year they take benefit from all the other promotions.

Interest in consumer choices grew up among marketers in the process of formulating a more general consumer behavior theory. Some of the factors marketing becoming an important element in society were mass production, mass distribution, and product branding. Consumer choice is that part of consumer behavior theory that focuses on how the individual consumer goes about making choices. [4]

Still, the possibilities of online advertisements for the Romanian web sites are limited. We have to take into account: search engines, banner webs and tops. The electronic magazines and the discuss groups are on one hand few as a number, but on the other hand they have a low number of subscribers (hundreds).

Also, the incomes of the Romanians should make them search for products that are suitable for their income, not for the ones that are expensive, even if we are so poor that we cannot afford the cheap ones.

As young researchers we wish to highlight the strong relationship between internet and marketing, the implications of the online environment at the marketing level. The behavior of the consumer is influenced by exogenous and endogenous factors, but the decision to buy is taken according to the information about the product that is shown, lately, on the internet.

In Romania doing shopping on Internet means fashion, pleasure and utility. Most of the sites that offer the possibility of doing shopping on-line had started from the idea of maintaining the traditional sales helped by the electronic environment or they had started a business that is only in the virtual environment. Even if the statistics present an evolution of the electronic trade over the year, its entering degree on Romania market is small enough than the other states. So, the electronic trade is at the begging of the growing stage and probably over 4-5 years we will truly talk about a stable trade market. The main problem in the Romanian online business advance it is represented by the clients themselves.

The Romanian buyers are very uncertain when it comes to buying online products and this thing comes beyond the wrong mentality that they have. We can also talk about the negative mentality of some persons in order to accept the technological process, without making reference at the concept of shopping online.

\section{CONCLUSIONS}

The study show that advertising on the behavior of buying and consume plays an important role in selling products. Also most of consumers are interested in brand products. It is found that temporary price discounts occupy an important place in buying decision, and sponsorship has a negative effect on buyers. Many consumers go at fairs and exhibitions attracted by the new products, by the producer's prices or the diversified supply. Very important to mention is the fact that the online advertising influences the buying decision.

Consumer behavior and advertising are dynamic fields, in terms of practice and scientific training. For example, the television commercials that appear in the year 2012 have little in common with those from the 1970s. Advertisements from this earlier period used modern techniques and were primarily informative. Advertising research styles have involved and advanced, partly through the influence of improved technology and access to advanced theories and methods. [8]

Romania, the country we live in, is ready for such market instrument only at a theoretical level, as there aren't the necessary resources for implementation of such an approach, being a subject far too distant from the realities we live.

\section{REFERENCES}

[1] Davis, J. J. (1993). Strategies for environmental advertising, Available from: http://www.emeraldinsight.com/journals.htm? articleid=856162\&show=abstract Accessed $:$ 2012-09-02

[2] de Mooij M. (2011). Consumer behavior and culture. Consequences for global marketing and advertising, Sage Publications, ISBN 978-1-4129-7990-0, Thousand Oaks, USA

[3] Dinu, G.; Dinu L.(2012) Trends of electoral behavior in CarasSeverin, "Zilele academice aradene", ISSN 1582-5442, Arad, Arad

[4] Hansen, F.; Christensen, S. R. (2007). Emotins, advertising and consumer choice, Copenhagen Business School Press, ISBN 978-87630-0198-4, Copenhagen, Denmark

[5] Hoyer, D. H; Macinnis D. J., (2010). Consumer behavior, SouthWestern, ISBN 1-800-354-9706, USA

[6] Rasool, M. S.; Hannan, M (2012). Impact of advertisement on consumer behavoir of FMCG in Lahore city, Available from: http://www.savap.org.pk/journals/ARInt./Vol.2(3)/2012(2.3-69).pdf Accessed: 2012-09-01

[7] Vitez, O., The influence of advertising on consumer buying behavior, Available from: http://www.ehow.com/facts_6948058_ influence-advertising-consumer-buying-behavior.html, Accessed: $2012-$ 06-20

[8] Zinkhan, G. (2011). Advertising research: the Internet, consumer behavior and strategy, Marketing Classic Press, ISBN 978-1-61311271-7, Decatur, USA 